\title{
Simulation Based Studies on the Integration of Battery-Electric Vehicles in Regional Bus Services
}

\author{
Felix Burmeister ${ }^{1}$, Dr.-Ing. Lars Schnieder ${ }^{2}$ \\ Institute of Transportation Systems, \\ German Aerospace Center (DLR) \\ Brunswick, Germany \\ ${ }^{1}$ felix.burmeister@dlr.de \\ ${ }^{2}$ lars.schnieder@dlr.de
}

\author{
Tamás Kurczveil \\ Institute for Traffic Safety and Automation Engineering, \\ Braunschweig University of Technology \\ Brunswick, Germany \\ kurczveil@iva.ing.tu-bs.de
}

\begin{abstract}
Around the world, more and more cities already have introduced electric-powered bus fleets or are planning to do so in the near future. Thus far, electrical-powered bus fleets have not yet been applied to regional bus services. This paper analyzes the boundary conditions of the operational integration of electrically powered bus fleets in regional bus services. The paper introduces a methodical approach which can be used to identify the optimum deployment strategy for electrical-powered buses which is a combination of technological factors (e.g. dimensions of energy storage and charging technology) the operational regime to be applied (e.g. routing and scheduling). The methodical approach is exemplarily instantiated with the analysis of sample data of a bus line in a topographically challenging region. The model-driven prognosis of the vehicle's state of charge is the basis for the definition of an optimum deployment strategy for electrical-powered buses on that line.
\end{abstract}

Keywords-public transport; regional bus service; transportation planning; electric busses; traffic simulation;

\section{MOTIVATION}

A major challenge in the integration of electrically powered vehicles into public transport operations lies in the currently existing constraints of the utilised energy storages. Seen in the light of optimized life cycle costs, the dimensions of the onboard energy storage need to be carefully considered. Dimensioning of an adequate on-board energy storage should reflect (a) requirements of operating ranges, (b) consideration of the expected lifetime of electrochemical energy storages which is determined by the number of charge/discharge cycles and the permissible depth of discharge and in consequence (c) the loading regime derived from the spatial and temporal use of charging infrastructure.

With respect to the operating ranges the current generation of electrically powered buses is capable of covering distances of up to three hundred kilometres in urban areas with a single charge. The highest operating range of an electrically powered bus communicated by a manufacturer is BYD's ebus-12 (Series 2015- vehicle range of $317 \mathrm{~km} \mathrm{[1]).} \mathrm{Each} \mathrm{business} \mathrm{case}$ for the introduction of electrically driven buses needs to consider the expected lifetime of electrochemical energy storages. High stress, in particular high depth of discharge significantly reduces the expected lifetimes of electrochemical energy storages. Currently used batteries in electric or hybrid vehicles endure only a number of several hundred to a few thousand discharge/charge cycles at full capacity utilization [4]. Under these conditions, it may not be possible to use the battery over the entire useful life of a regular bus (12 years [3]).

In order to fulfil the required operating range while keeping the expected lifetime of electrochemical energy storage at a reasonable level, different strategies can be applied. (a) Adjustment of charging regimes to recharge the batteries during operations. (b) Dimensioning a battery larger than necessary and (c) Replacement of batteries at the end of their useful life.

Experience with hybrid vehicles shows, that the number of potential charge/discharge cycles increases far greater than the costs caused by the corresponding increase of employed capacity. Limiting the depth of discharge by using only a few percent of the installed capacity, the number of potential cycles can increase in the range of several hundred thousand (strategy b). This allows lifetimes of hybrid vehicles of more than ten years.

Batteries significantly determine investment costs and will continue to do so in the coming decade. Studies conducted in the years 2009-2013 [2] predict that over the next ten years the investment costs of lithium-based vehicle batteries will decrease to about 200 to $300 €$ per $\mathrm{kWh}$. However, for a vehicle as quoted in [1], with an energy storage capacity of 324 $\mathrm{kWh}$ (equivalent to a vehicle range of $317 \mathrm{~km}$ ), this still means costs for the energy storage of around 60,000 to $100,000 €$. That needs to be set into relation to the current investment costs of about $250,000 €$ for a single 12-m bus (diesel) [3]. That suggests that even if recharging a battery of a vehicle during the day is not mandatory, additional charges however can, for the purposes of increasing the battery life or reducing the required storage dimensions, be economically viable.

Within the project "emil" (Elektromobilität mittels induktiver Ladung, electric mobility through inductive charging), the process of dimensioning the charging infrastructure was carried out successfully for a city bus line with the priority of maintaining currently existing time-tables. (See [5] and [6]). The optimization process involved the placement of charging stations at vehicle stops, to optimize 
battery life by controlled intermediate charging along the line. It was demonstrated that at frequent stops with high passenger transfer rates, the regular durations of halts can be long enough to recharge $10 \%$ or more of the energy that is demanded for one driving cycle. Together with the time spent at the final stop (including pauses for the driver), the battery can be fully recharged before the start of the next driving cycle. Therefore, the strategy to adjust the charging regime proves to be effective for rural bus services. With that work as the basis, it is the aim of this paper to expand these analyses and optimisation processes towards regional traffic. According to existing definitions [11], this includes transport which goes beyond the boundaries of cities and their surrounding communities, but usually do not exceed distances of $50 \mathrm{~km}$ or trip durations of more than one hour.

\section{SPECIFICATION OF REGIONAL BUS SERVICES}

\section{A. Representative line services}

In the following, it will be explained which special aspects have to be taken into consideration for the estimation of vehicles' energy consumption and possible charging regimes for regional bus services. The comparison is made to urban transport. For this purpose, three exemplary bus lines will be compared. On the one hand, this is the line M19 of the local public transport operator in the city of Braunschweig (Braunschweiger Verkehrs-GmbH, BSVG) as in [6] and on the other hand, the lines 450 and 840 of a regional bus operator (Regionalbus Braunschweig GmbH, RBB). As shown in Table I, line M19 runs on a $12 \mathrm{~km}$ long circular route. The other two, line $450(24.5 \mathrm{~km})$ and line $840(33 \mathrm{~km})$, run between two final stops. These final stops are located in the towns of Herzberg am Harz (450), Sankt Andreasberg (both) and ClausthalZellerfeld (840) in the German mountain range Harz. These two routes are subject to a special topographic influence, which will be dealt with further on (2).

TABLE I. COMPARISON OF LINES 19 (BSVG) AND 450, 840 (RBB)

\begin{tabular}{|l|l|l|c|}
\hline & \multicolumn{1}{|c|}{ M19 } & \multicolumn{1}{|c|}{$\mathbf{4 5 0}$} & $\mathbf{8 4 0}^{*}$ \\
\hline Route length & $\begin{array}{l}12 \mathrm{~km} \\
\text { (circle) }\end{array}$ & $24.5 \mathrm{~km}$ & $33 \mathrm{~km}$ \\
\hline Duration (single trip) & $39 \mathrm{~min}$ & $56 \mathrm{~min}$ & $<54 \mathrm{~min}$ \\
\hline Resulting avgerage velocity & $23 \mathrm{~km} / \mathrm{h}$ & $26 \mathrm{~km} / \mathrm{h}$ & $>37 \mathrm{~km} / \mathrm{h}$ \\
\hline Interval (peak traffic hours) & $10 \mathrm{~min}$ & $60 \mathrm{~min}$ & $120 \mathrm{~min}$ \\
\hline Number of stops & 27 & 34 & 26 \\
\hline Mean distance between stops & $0.46 \mathrm{~km}$ & $0.72 \mathrm{~km}$ & $1.27 \mathrm{~km}$ \\
\hline Altitude diff. between final stops & $0 \mathrm{~m}$ & $350 \mathrm{~m}$ & $60 \mathrm{~m}$ \\
\hline $\begin{array}{l}\text { Altitude difference between highest } \\
\text { and lowest point }\end{array}$ & $10 \mathrm{~m}$ & $350 \mathrm{~m}$ & $360 \mathrm{~m}$ \\
\hline Accumulated altitude differences & $20 \mathrm{~m}$ & $360 \mathrm{~m}$ & $1200 \mathrm{~m}$ \\
\hline
\end{tabular}

A variant of line 840 runs on a shorter route between the final stops (overall interval $60 \mathrm{~min}$ ). The shorter route is not considered in this paper

\section{$B$. Influences on power consumption}

\section{1) Drive cycle:}

With larger distances between stops, driving time has a higher share in the overall trip duration. According to fewer limitations in speed on non-urban roads and a lower impact of intersections and other road users, the operational profile will show significantly higher average speeds.
It is to be investigated, whether the drive power which has to be applied by a bus is higher in regional traffic than in urban traffic. Possibly, driving resistance might exceed the losses caused by the start-stop operations in city traffic, as for example air resistance increases with the square of the vehicle velocity. Recuperation, the recovery of energy during the event of deceleration, which electric vehicles are usually capable of, is essential in this matter.

Thereby, a perceptible difference can already be discovered between the routes in inner cities and suburbs. Test cycles for buses (Standardized on-road test cycles, SORT [7]) already exist for these areas. A distinction is made between the downtown area with heavy traffic impact (SORT 1), the suburban area with light traffic impact (SORT 3) and a transition between these two areas (SORT 2). Relevant details on these test cycles and measured consumption of tested vehicles under such conditions is shown in Table II.

TABLE II. SORT CYCLES AND EXAMPLARY CONSUMPTIONS

\begin{tabular}{|l|l|l|l|}
\hline \multicolumn{5}{|c|}{ Specified test cycles [7] } \\
\hline Cyle & SORT 1 & SORT 2 & SORT 3 \\
\hline $\begin{array}{l}\text { Area } \\
\text { (influence of traffic) }\end{array}$ & $\begin{array}{l}\text { Downtown } \\
\text { (heavy) }\end{array}$ & $\begin{array}{l}\text { City } \\
\text { (mixed) }\end{array}$ & $\begin{array}{l}\text { Suburb } \\
\text { (light) }\end{array}$ \\
\hline Average velocity & $12,1 \mathrm{~km} / \mathrm{h}$ & $18 \mathrm{~km} / \mathrm{h}$ & $25,3 \mathrm{~km} / \mathrm{h}$ \\
\hline Maximum velocity & $40 \mathrm{~km} / \mathrm{h}$ & $50 \mathrm{~km} / \mathrm{h}$ & $60 \mathrm{~km} / \mathrm{h}$ \\
\hline Mean stop distance & $0,172 \mathrm{~km}$ & $0,303 \mathrm{~km}$ & $0,476 \mathrm{~km}$ \\
\hline Relative stop duration & $39,7 \%$ & $33,4 \%$ & $20,1 \%$ \\
\hline \multicolumn{2}{|c|}{ Consumption of exemplary vehicles depending on drive technology } \\
\hline ICE (diesel) [8] & $0,551 / 1 \mathrm{~km}$ & $0,41 / \mathrm{km}$ & $0,361 / \mathrm{km}$ \\
\hline ICE (ethanol) [9] & $0,91 / \mathrm{km}$ & $0,791 / \mathrm{km}$ & $0,711 / \mathrm{km}$ \\
\hline $\begin{array}{l}\text { Hybrid without } \\
\text { start-stop system [9] }\end{array}$ & $0,731 / \mathrm{km}$ & $0,631 / \mathrm{km}$ & $0,631 / \mathrm{km}$ \\
\hline $\begin{array}{l}\text { Hybrid with } \\
\text { start-stop system [9] }\end{array}$ & $0,61 / \mathrm{km}$ & $0,621 / \mathrm{km}$ & $0,621 / \mathrm{km}$ \\
\hline Battery-electric [10] & $1,15 \mathrm{kWh} / \mathrm{km}$ & $1,14 \mathrm{kWh} / \mathrm{km}$ & $1,15 \mathrm{kWh} / \mathrm{km}$ \\
\hline
\end{tabular}

Hybrid vehicles are able to recuperate. With the usage of that technology, the difference between the energy consumption in urban areas and in the suburb drops noticeably, as shown for exemplary vehicles listed in Table II. Deactivating the internal combustion engine (ICE) during stops (start-stop system) in addition, influences of traffic on the energy consumption becomes unnoticeable. The same applies for full-electric vehicles. Measured consumptions are almost identical at all three test cycles.

Comparing the specifications of the SORT cycles with the given data for the two regional bus lines in Table I, it seems possible that the power consumption of vehicles on the urban bus line M19 might be estimated through cycles of SORT 2 and SORT 3. For the line 450 however, there already is a major difference in the average distance of stops, and it can be assumed that this will also result in different stop durations. The same applies for the line 840 which also has a much higher average velocity than any of those featured by these cycles. By German law (StVO § 3), regular omnibuses are allowed to travel with $80 \mathrm{~km} / \mathrm{h}$ if seats can be provided to all passengers. Most of all, the SORT cycles do not account for the differences in altitude. The estimation of the power consumption of busses servicing regional bus lines 450 and 840 will require a different, specific simulative approach. 


\section{2) Line Topograpy:}

Large differences in altitude across the track influence the amounts of required energy in a high degree. Depending on the charging regime, this results in significant differences in battery levels between lower and higher track points and therefore a greater requirement in battery capacity.

A difference of about 350 meters in altitude exists between the final stops of line 450 . The altitude profiles of the three lines are compared in Fig. 1. For an empty 12-meter solo bus with a weight of 13 tons, already, $12.9 \mathrm{kWh}$ need to be applied as potential energy for overcoming this height difference of $350 \mathrm{~m}$ while ascending the mountain range. This alone represents the dimension of the amount of energy that is forecast in the project emil for a single regular circulation of a moderately occupied bus of the line M19.

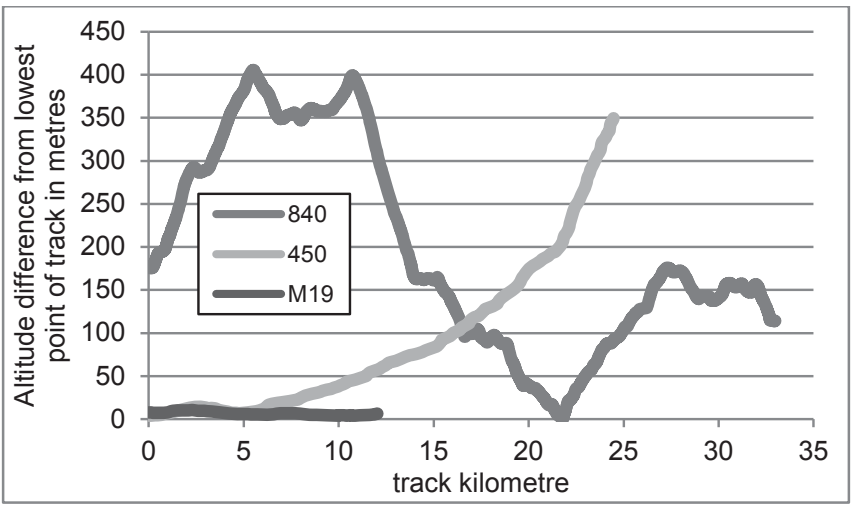

Fig. 1. Comparison of altitude profiles of bus lines M19 (BSVG) and 450, 840 (RBB)

\section{3) Recuperation:}

According to lower number of crossings, bus stops and lower traffic density, the number of events where energy is recovered from movement decreases outside the metropolitan area by the fewer events of braking. However, kinetic energy which determines the amount of recoverable energy increases with the square of the vehicle velocity. On flat roads, the importance of recuperation is generally smaller compared to city areas, as the measurements of Table II show. The situation is different on the designated routes with large height differences. In the recuperation at a constant speed on downhill sections (e.g. track kilometres 10.4 to 21 of line 840), potential energy can be recovered from a previous ascent (track kilometres 0 to 5.5).

\section{Influences on the charging regime}

The number of possible locations for an electrical recharging is severely limited in rural areas according to the limited existence of electrical infrastructure (power grid).

With lower intervals of busses servicing a single line, the efficiency of charging infrastructure decreases with fewer potentials of synergies through line overlays that allow the use of existing infrastructure for vehicles of other lines.

Additionally, recuperation influences the economy of charging infrastructure. Travelling longer downhill-sections, recuperation will allow that the vehicle battery will be charged up by a great amount of energy. Therefore, placing a charging station in front of that downhill section might prove rather unprofitable.

\section{Auxiliary equipment}

Influences of auxiliary equipment such as air conditioning, which may differ in configuration and operation to those in urban vehicles, as well as possibly different degrees of passenger occupation, are to be examined in detail.

\section{ANALYSIS OF A TOPOGRAPHICALLY CHALLANGING TRACK}

\section{A. Modeling of the vehicle's energy consumption}

To determine the necessary dimensions of battery capacity, the energy consumption of the corresponding vehicle during the period of deployment is to be analysed. As in previous work [6], the mechanical energy model of the vehicle will be used as a basis for this analysis. The mechanical energy of the vehicle $E_{\text {Veh }}[\mathrm{k}]$ for an arbitrary discrete time k results from the sum of the kinetic, potential and rotational energy (see Eq.1):

$$
E_{\mathrm{Veh}}[k]=E_{\mathrm{kin}}[k]+E_{\mathrm{pot}}[k]+E_{\text {rot,int }}[k]
$$

Within the scope of the project emil, the potential energy was regarded as negligible due to the small height differences within the city Braunschweig. This is not possible for the lines 450 and 840 . From the change in the vehicle energy content $\Delta E_{\mathrm{var}}[\mathrm{k}]$ follows the amount of mechanical energy that needs to be conveyed by the drive. The amount corresponds to the difference of the vehicular mechanical energy between two discrete points in time $[\mathrm{k}]$ and $[\mathrm{k}+1]$ with inclusion of the energy losses $\Delta E_{\text {Loss }}[\mathrm{k}]$ within the same period (see Eq. 2).

$$
\Delta E_{\mathrm{Var}}[k]=E_{\mathrm{Veh}}[k+1]-E_{\mathrm{Veh}}[k]-\Delta E_{\mathrm{Loss}}[k]
$$

The calculation of energy losses $\Delta E_{\text {Loss }}[\mathrm{k}]$ includes, for example, air flow, and rolling resistance and the consumption of auxiliary equipment. Vehicle and ambient parameters must be adjusted according to the required accuracy for each analysis.

The variation of the energy content in the vehicle battery $E_{\text {bat }}$ is subject to additional degrees of efficiency for energy recovery $\eta_{\text {Rekup }}\left(E_{\text {var }}[\mathrm{k}]>0\right)$ and drive $\eta_{\text {Drive }}\left(E_{\text {var }}[\mathrm{k}]<0\right)$ that include the losses of energy conversion and transmission in the drive train as well as the battery. The resulting variation of the energy content is obtained according to the equations 3 and 4 .

$$
\begin{array}{ll}
E_{\text {Bat }}[k+1]=E_{\text {Bat }}[k]+\Delta E_{\text {Var }}[k] \cdot \eta_{\text {Rekup }} & \text { für } \Delta E_{\text {Var }}[k]>0 \\
E_{\text {Bat }}[k+1]=E_{\text {Bat }}[k]+\Delta E_{\text {Var }}[k] \cdot \eta_{\text {Drive }}^{-1} & \text { für } \Delta E_{\text {Var }}[k]<0
\end{array}
$$

Losses also occur during the supply of power to the vehicle (charging) and withdrawal of energy from the vehicle (discharge). The latter would be considered in the transfer of energy to another vehicle. The energy content of the vehicle battery increases or decreases with the corresponding equations 5 and 6 by a specific rate, depending on the charge power 
$P_{\text {Charge }}$ or discharge power $P_{\text {Discharge }}$, charging efficiency $\eta_{\text {Charge }}$ or discharging efficiency $\eta_{\text {Discharge }}$ and the time duration $\mathrm{t}$.

$$
\begin{gathered}
E_{\text {Bat }}[k+1]=E_{\text {Bat }}[k]+P_{\text {Charge }} \cdot \eta_{\text {Charge }} \cdot \Delta t \\
E_{\text {Bat }}[k+1]=E_{\text {Bat }}[k]+P_{\text {Disch arge }} \cdot \frac{1}{\eta_{\text {Discharge }}} \cdot \Delta t
\end{gathered}
$$

Based on empirical data required for the vehicle model in project emil, parameters were determined so that the energy variation of the real bus put into service was precisely replicated.

Variations in the shares of power consumption that can be calculated with the final model and parameter set are shown for an exemplary calculation for a $12-\mathrm{m}$ bus below in Fig. 2. That calculation comprises rolling resistance, air resistance, and the losses in the overall efficiency chain in-between batteries and the wheels that were broke down into those related to acceleration and recuperation (no mechanical braking) and others (those losses related to rolling- and air resistance during acceleration and cruise). Those calculations were done for the three SORT cycles and an exemplary different track with the length of $3 \mathrm{~km}$ and one single drive cycle based on an acceleration to $80 \mathrm{~km} / \mathrm{h}$, an ongoing cruise with constant speed and a final recuperation (deceleration) until full stop. That last cycle is meant as an example for a part of a cycle that might be utilised for regional traffic.

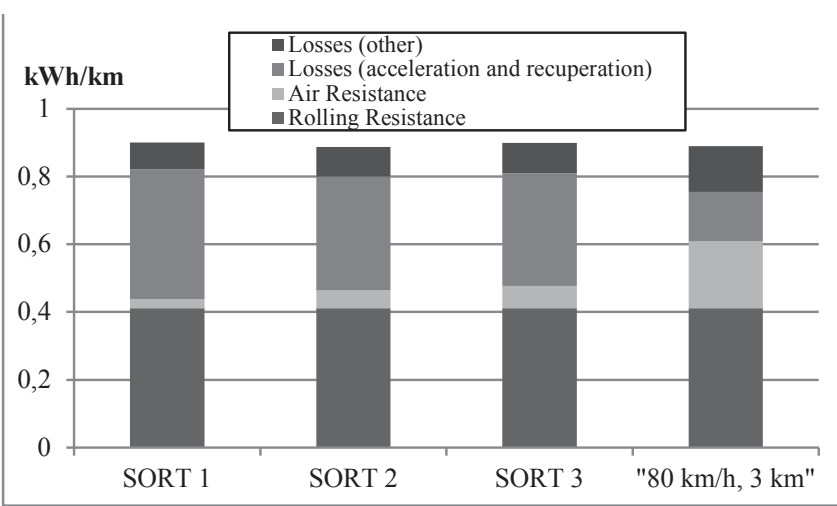

Fig. 2. Shares in the power consumption of a 12-m electric bus

As shown in Fig. 2, the amount of energy that is being consumed to overcome driving resistances and corresponding electromechanical losses does not vary widely between the different cycles. Here, rolling resistance is regarded as only depending on track length and therefore is a constant value. What varies, are shares of losses and air resistance, the latter becoming an important quantity at higher mean speeds. With higher speeds and lower numbers of decelerations (stops along the line), recuperation becomes far less important on flat tracks in regional areas.

\section{B. Analysis of line 840}

With the vehicle energy consumption and parameters estimated for an electric bus from previous work [6] an exemplary energetic analysis will be performed for the line 840 under the following constraints: Line 840 will be analysed isolated to restrict complexity. Based on the published timetable, a minimum of two vehicles are needed to service the line. One vehicle will only service the shortened route, while a second one drives on the regular route 12 out of 16 times. In reality, vehicles do change between different lines. Here, they will not. The second vehicle's energy demand on the regular route is subject of the analysis.

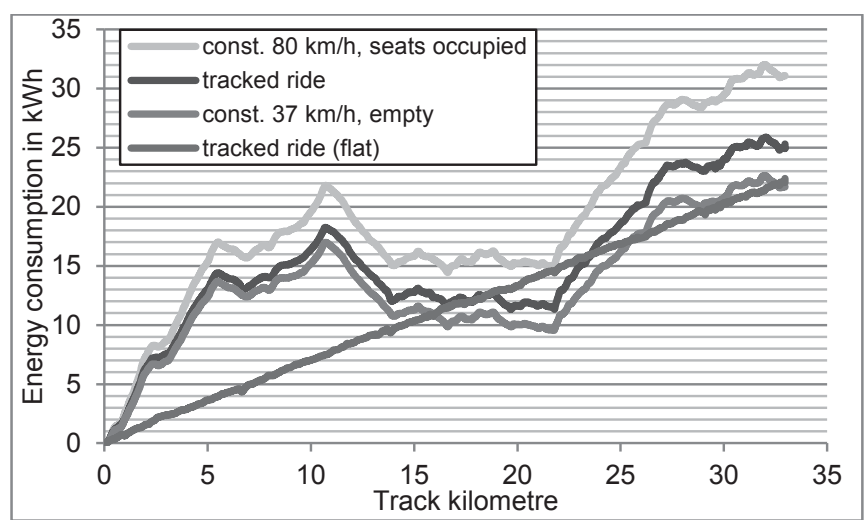

Fig. 3. Cumulated energy consumption calculated for rides on the track of line 840 from Sankt Andreasberg to Clausthal-Zellerfeld

In Figure 5, results are shown for rides departing from Sankt Andreasberg under different conditions. The trend plots show the electric energy consumed over the course of the track (i.e. the energy drawn from the battery). A single gps-track is given for a ride departing at 3:34 pm on a Monday. The measured speed-profile was also recalculated without the altitude-profile ("flat") to show the high impact of the topography. Two profiles with constant speed are added to show the maximum of foreseeable variance in energy consumption. On the one hand, we see a profile with the minimum average velocity to complete the track within schedule $(37 \mathrm{~km} / \mathrm{h})$ with an empty vehicle for the lowest power consumption. On the other hand we see a profile for a bus with every seat being occupied (additional 2.4 tons of weight) continuously driving at $80 \mathrm{~km} / \mathrm{h}$ (maximum speed allowed for regular omnibuses), a worst case scenario, not accounting the rare occurrences of acceleration and deceleration.

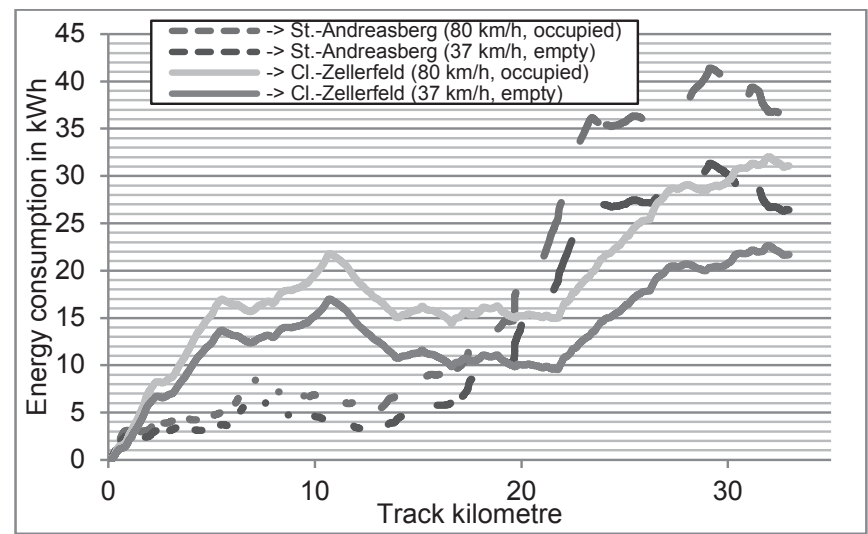

Fig. 4. Cumulated Energy consumption for line 840 in both directions, Clausthal-Zellerfeld (as in Fig. 5) and Sankt Andreasberg 
As the two final stops are located at different altitudes, there is a difference in the power consumption of the return trip to Sankt Andreasberg. In Figure 6, the two estimates for a low and a worst-case degree of average velocity and passenger occupation are shown for both directions.

Due to the topography, at least $14.6 \mathrm{kWh}$ (empty vehicle, $37 \mathrm{~km} / \mathrm{h}$ ) are drawn from the battery to overcome the additional driving resistances, a difference of up to $30 \%$. Also, the battery capacity does need greater dimensions. As for example in the worst-case scenario in the return trip, $36.5 \mathrm{kWh}$ of energy are consumed in between the final stops. Yet, at a point on the track, $40.8 \mathrm{kWh}$ are discharged from the battery to cover a high ascent before recharging the battery partially on the descent that follows up.

Both the overall increased power consumption and necessarily higher battery capacity are constraints regarding the electrification of regional bus services. The ability of electrical vehicles to recuperate, on the other hand, leads to a major potential in topographically challenging regions. With the previous calculations, it can be estimated that recuperation leads to energy savings between $32 \%$ and $41 \%$ for the outgoing trips (38\% for the gps-tracked one) and still $25 \%$ to $34 \%$ for the return-trips. These figures are comparable, if not succeeding the ones for energy savings of hybrid vehicles in urban areas that usually range between $15 \%$ and $30 \%$ (e.g. [15]).

For each trip, the vehicle battery would need to be recharged with $22 \mathrm{kWh}$ to $36.5 \mathrm{kWh}$. Under these conditions, a vehicle as discussed in [1] that features a battery with $324 \mathrm{kWh}$ would be able to operate 5 to 6 round-trips. For the strategy of having busses servicing the line without recharging, the battery capacity of the vehicle would need to be higher or other methods of optimisation would need to be considered.

For the strategy to recharge the bus during operation, the durations of stops need to be analysed. The bus line 840 belongs to the routes in the mountain range Harz that is mostly used by students and tourists. Hence, the passenger occupancy varies heavily throughout the day as well as the seasons. On the tracked ride, as an example, a maximum of three passengers were counted and the bus would pass through the majority of bus stops without coming to a halt. Under these conditions, charging facilities at stops on the track will not be feasible. Therefore, in a first step, only the regular pauses at the final stops will be accounted for. The pauses after every trip along the regular track of line 840 , there is a pause between 0 minutes and 16 minutes based on the published time-table (average: 9 minutes). The charging power of the specified bus [1] with $324 \mathrm{kWh}$ is $60 \mathrm{~kW}$, which neither a very low nor a very high value. During all pauses of the day, a total of $210 \mathrm{kWh}$ can be recharged. This means, that placing two charging stations at the final stop would eventually enable this type of bus to operate throughout the day even under worst case conditions. It would last for 8 to 10 round-trips which is more than necessary. Still, the low pause times such as 0,4 and 8 minutes do not allow to fully recharge the vehicle after every single trip. To aim for a minimum of necessary battery capacity which is not much higher as the energy demand for one single trip, in an optimisation process, additional possibilities need to be considered that either increase the opportunities (times) for recharging or decrease the overall power consumption of the line 840 .

\section{METHODICAL APPROACH FOR OPTIMIZATION}

\section{A. Considered optimization processes}

In addition to the adjustment of the charging infrastructure, in the context of this paper the possibilities will be considered that perform adaptions on the operational level of the driving task (especially accelerations and decelerations), the tactical level of the driving task (e.g. use of time advances for additional charging) and the strategic level of the driving task (e.g. altered routes). In this case, also possible influence on service quality perceived by passengers has to be considered.

\section{1) Adaption on the strategical level:}

Actions at this level include changes made to routes and time tables. Here, however, any adverse effects on service quality must be taken into account perceived by passengers, (eg. longer travel times). In addition, if necessary - especially in topographically challenging regions - the opportunity to exchange energy between vehicles has to be considered. This can, provided an appropriate infrastructure is available, either done directly from vehicle to vehicle or via a stationary energy storage. Here, a scenario can be, for example, the transmission of energy from a vehicle on or after a downhill travel to a vehicle on or before of an incline.

\section{2) Adaption on tactical level:}

Actions at this level must involve the risk that at unusually high traffic and passenger rates, a vehicle tour cannot be finalized due to the limited energy storage. This may require the testing of alternated routes or a replacement on the track by an additional vehicle hold available.

\section{3) Adaption on operational level:}

Actions at this level include the drive objectives for a specific vehicle. This may be the adaptation of vehicle speeds and possible changes in acceleration and deceleration values. The aim is to minimize the required driving power for a ride, or to maximize the possible recuperation.

\section{B. Technical realization (optimization tools)}

Many of the processes stated before relate to traffic, traffic infrastructure or demand for visualisation of the same. Therefore, within the framework of the project emil, it was decided that a planning tool that comprises the optimisation processes stated before, should be based on the analysis of microscopic simulated traffic scenarios which are calibrated with raised road and public circulation data. For this purpose, the microscopic traffic simulation tool SUMO (Simulation of Urban Mobility) [12], developed by the German Aerospace Center (DLR), was chosen and already extended by necessary, additional models such as electric drives and charging stations and functions as those to analyse energetic performance [13]. 
Optimizing processes with adjustments on tactical and strategical level can be implemented with the extension of SUMO in an appropriate planning tool.

SUMO allows the interaction with a running simulation which includes adaption of parameters from vehicles as well as infrastructure. This meets the requirements for testing tactical interventions in which particular schedules and routes are to be adjusted, that are linked to specific vehicles. Furthermore, it is possible to equip vehicles with (virtual) "devices". This enables, for example, the collection of additional data such as the vehicle energy consumption, but also to retroactively affect driving behaviour. This forms the basis for optimizing processes with engagement at the operational level, as adjusting the speed and acceleration values as a function of position, battery levels and other conditions. Furthermore, these virtual devices allow the modelling of energy transfer: The withdrawal of energy from the electric-powered vehicle and in particular the intermediate storage and final transfer to another vehicle.

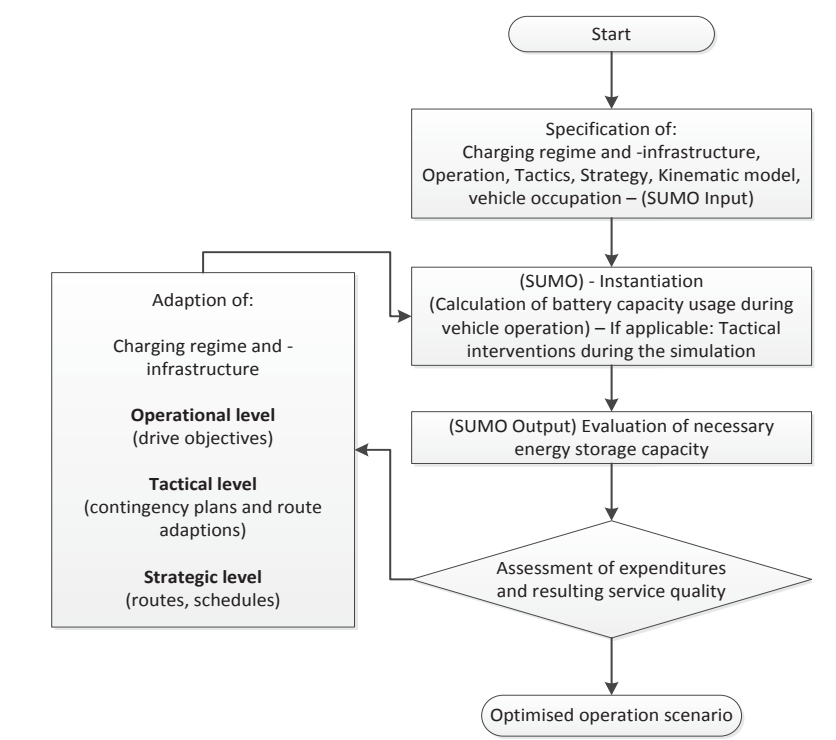

Fig. 5. Extended optimisation process in SUMO

The optimization process, which results from the use of SUMO considering optimizations at the operational and tactical levels, is shown in Fig. 4.

\section{CONCLUSION AND OUtLOOK}

With the introduction of electrical-driven buses to regional bus operations public transport operators face new challenges. This paper suggests a methodical approach which can be used to determine an optimum deployment strategy for new vehicle concepts in these operational conditions. A first analysis of empirical data revealed causal relations which have to be considered in further investigations. For operations of buses in urban scenarios the microscopic traffic simulation SUMO has proven to be an effective tool to assess operational feasibility of technical layouts (e.g. dimensioning of vehicle and infrastructure components) as well as the operational concepts of integrating battery-electric vehicles into urban bus operations. Future work will be directed towards modelling regional bus lines in the simulation tool in order to obtain quantitative data to optimize both technical layout as well as the operational regime of battery-electric vehicles in the context of regional bus services. Furthermore modelling total costs of ownership of different strategic deployment options should be performed in order to assess their economic feasibility.

\section{REFERENCES}

[1] BYD Europe B.V. (2015, Jamuary) BYD EBUS-12 specification [Website] http://www.bydeurope.com/vehicles/ebus/types/12.php

[2] Muenzel, Valentin; Mareels, Iven; de Hoog, Julian: "Affordable batteries for green energy are closer than we think". The Conversation (2014) [Website] http://theconversation.com/affordable-batteries-forgreen-energy-are-closer-than-we-think-28772

[3] Leuthard, Helmut: „Betriebswirtschaftlich optimale Nutzungsdauer von Linienbussen“. Der Nahverkehr 09/2008, pp. 33 - 37.

[4] Thomas B. Reddy, Linden's Handbook of Batteries, McGraw-Hill, 2011

[5] Meins, J.; Soyck, F.; Engel, B.; Kurczveil, T.; Schnieder, E.: „Application of high-power inductive charging of electric buses in scheduled line service." HEV2014 - 11. Symposium Hybrid- und Elektrofahrzeuge, Braunschweig, Deutschland, Februar 2014 HEUREKA 2014 - Optimierung in Verkehr und Transport, Stuttgart, 2.3. April 2014; pp. 510-523.

[6] Kurczveil, Tamas; Schnieder, Lars: „simulationsbasierte Planungsprozesse für die betriebliche Eingliederung induktiv geladener Busse in den Betrieb“. Der Nahverkehr 32 (2014) 12, pp. 24 - 29.

[7] International Association of Public Transport: UITP Project 'SORT' Standardized on-road test cycles (2014)

[8] EvoBus GmbH, Mercedes-Benz Omnibusse: „Mercedes-Benz BlueTec ${ }^{\circledR}$ Engines and EEVAhead of its time" (09.2010) [Brochure]

[9] Wikström1, Martina; Folkesson, Anders; Alvfors, Per: "First experiences of ethanol hybrid buses operating in public transport", World Renewable Energy Congress 2011 -Sweden (05.2011)

[10] van Goethem, Sam; Koornneef, Gertjan; Spronkmans, Stefan: "Performance of Battery Electric Buses in Practice: Energy Consumption and Range, Behavioural and Societal Sciences TNO 2013

[11] Personenbeförderungsgesetz (PBefG) $\$ 8$ (,Förderung der Verkehrsbedienung und Ausgleich der Verkehrsinteressen im öffentlichen Personennahverkehr“", 2013)

[12] Krajzewicz, Daniel; Erdmann, Jakob; Behrisch, Michael; Bieker, Laura: "Recent Development and Applications of SUMO - Simulation of Urban Mobility". International Journal On Advances in Systems and Measurements, 5 (3\&4), pp 128-138, 2012

[13] Kurczveil, T.; Álvarez López, P.; Schnieder, E.: Implementation of an Energy Model and a Charging Infrastructure in SUMO. Simulation of Urban Mobility, pp. 33-43, Novembre 2014. Springer Belin Heidelberg.

[14] Graser, A., Asamer, J., \& Ponweiser, W. (2015). The Elevation Factor: Digital Elevation Model Quality and Sampling Impacts on Electric Vehicle Energy Estimation Errors. MT-ITS 2015, Budapest, Hungary.

[15] Public Service Bus Systems with electric Propulsion - Potiontial for Emissions-free Mobility, pp. 100-109, DVV Media Group/Deutscher Verkehrs-Verlag GmbH, 2007, ISBN 978-3-7771-0366-2 